\title{
2.1 Million More Childless U.S. Women Than Anticipated
}

Kenneth M. Johnson

$\mathrm{I}$ n 2016, there were $\mathbf{2 . 1}$ million more childless women of prime child-bearing age than anticipated. The 19.5 million women age 20-39 in 2016 who had never given birth was 12 percent more than demographers would have expected given child-bearing patterns just before the Great Recession. In 2016, there were 7 percent more women 20-39 than ten years earlier, but 22 percent more who had never had a child.

In 2016, there were also 1.8 million fewer women age 20-39 who had given birth to two or more children, some 10 percent fewer than expected given pre-recession trends. The cumulative result of these trends was $\mathbf{4}$ million fewer U.S. births between 2008 and 2016 than had pre-recession fertility rates been sustained. The Great Recession was certainly a factor in this, but changing social and cultural attitudes might also have been influential.

A critical question now is: how many of the 4 million fewer births have been delayed and will eventually occur, and how many will be foregone? The answer has important social and policy implications for the larger society that will be influenced by the fertility choices these women make in the next few years.

\section{MORE CHILDLESS AND FEWER WITH KIDS AMONG WOMEN 20-39 COMPARED TO TRENDS JUST BEFORE THE RECESSION}

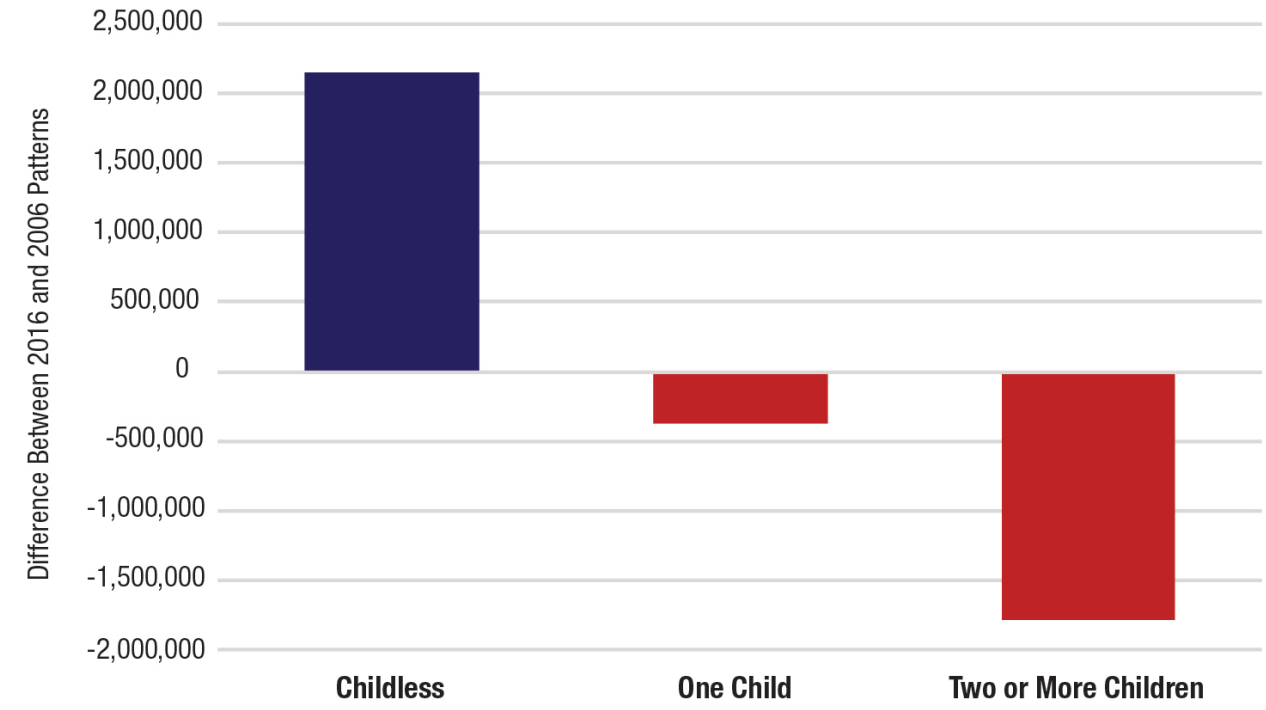

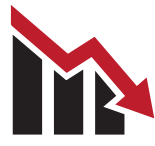

The Great Recession continues to influence U.S. demographic trends.

See Related Publications at carsey.unh.edu

D June 2017, New Data Show U.S. Birth Rate Hits Record Low

- June 2016, U.S. Births Remain Low as the Great Recession Wanes: More Than Three Million Fewer Births and Still Counting

- December 2014, The Hidden Cost of the Recession: Two Million Fewer Births and Still Counting

\section{About the Author}

Kenneth M. Johnson is senior demographer at the Carsey School of Public Policy, professor of sociology at the University of New Hampshire, and an Andrew Carnegie Fellow.

Analysis: K.M. Johnson, Carsey School, University of New Hampshire Data: Current Population Survey, U.S. Census

Huddleston Hall • 73 Main Street • Durham, NH 03824 carsey.unh.edu • 603.862.2821
TTY USERS: DIAL 7-1-1 OR

1-800-735-2964 (RELAY N.H.) 